\title{
Drug metabolism-related genes as potential biomarkers: analysis of expression in normal and tumour breast tissue
}

\author{
Vanesa Martinez $\cdot$ Susan Kennedy $\cdot$ Padraig Doolan $\cdot$ Patrick Gammell \\ Helena Joyce · Elaine Kenny · Jai Prakash Mehta · Eoin Ryan • \\ Robert O'Connor · John Crown · Martin Clynes · Lorraine O'Driscoll
}

Received: 6 July 2007/ Accepted: 16 August 2007/Published online: 27 September 2007

(C) Springer Science+Business Media, LLC 2007

\begin{abstract}
The complex role of drug metabolism-related enzymes and their possible influence in cancer development, treatment and outcome has not yet been completely elucidated. There is evidence that these enzymes can activate certain environmental procarcinogens to more toxic derivatives and thus a role has been proposed for them in carcinogenesis. The fact that they can also inactivate a number of chemotherapeutic drugs has raised the possibility of these enzymes influencing the sensitivity of tumour cells to anticancer agents. In this report, we analyse the expression of drug metabolism-related genes within a whole genome microarray study of 104 breast cancer and 17 normal breast specimens. Kaplan-Meier survival curves, Chi-squared, and Cox Regression analyses were used to identify associations between expression of gene transcripts and patients' clinicopathological and survival data. Our results show that several of these genes are significantly expressed in both normal and tumour tissue; in many cases, expression is altered in the tumour specimens as compared to normal breast tissue. Moreover, expression of ARNT2 and GST A1 was correlated with prognosis. Kaplan-Meier analysis showed expression of ARNT2 mRNA to correlate significantly with favourable disease outcome for patients, in terms of
\end{abstract}

V. Martinez and S. Kennedy contributed equally.

V. Martinez - P. Doolan · P. Gammell - H. Joyce - E. Kenny ·

J. Prakash Mehta - E. Ryan - R. O'Connor · J. Crown .

M. Clynes · L. O’Driscoll $(\bowtie)$

National Institute for Cellular Biotechnology (NICB), Dublin

City University, Dublin 9, Ireland

e-mail: Lorraine.ODriscoll@dcu.ie

S. Kennedy $\cdot$ J. Crown

St. Vincent's University Hospital, Dublin 4, Ireland both their disease-free survival $(P=0.0094)$ and overall survival $(P=0.0018)$ times from diagnosis, while detection of GST A1 mRNA correlated with shortened disease-free survival $(P=0.0131)$ and overall survival $(P=0.0028)$. Multivariate analysis indicated GST A1 expression to be an independent prognostic factor for overall survival $(P=$ 0.045). Our results suggest a possible use of ARNT2 and GST A1 as prognostic breast cancer biomarkers.

Keywords Biomarkers · Breast · Drug metabolism · Microarrays · Prognostic factors

\section{Introduction}

Drug metabolism-related enzymes protect the body from the toxic effects of endogenous and exogenous compounds. Their ability to metabolise carcinogens and anticancer drugs lends them the potential to influence tumour development and sensitivity to chemotherapy and therefore tumour progression and treatment outcome [1-5].

Cytochromes P450 are a family of enzymes implicated in the biotransformation of both xenobiotics and endogenous compounds [6]. Their primary functions are the synthesis of steroids and bile acids and the detoxification of many substances, such as drugs and environmental agents. Cytochromes P450 are considered the most important enzymes carrying out Phase I reactions, where substrates are prepared for conjugation and excretion, while several studies have proposed a role for these enzymes in carcinogenesis, cancer progression and treatment outcome [7-10]. Glutathione (GSH) is the major soluble antioxidant present in mammalian cells and can also be conjugated to endogenous compounds or xenobiotics as means of detoxifying them. It has also been reported as a mediator in signalling pathways 
that modulate cell proliferation, differentiation and apoptosis [2, 11, 12].

Expression of enzymes involved in drug metabolism has been detected in every different type of tissue studied to date, both normal and tumour; techniques employed for detection include RT-PCR, Western blot, immunocytochemistry and immunohistochemistry. Enzymatic activity measurements have also been performed in tissue homogenates and/or isolated microsomes (cell fractions mainly composed of endoplasmic reticulum membranes). Although the presence of metabolic enzymes in both normal and tumour tissue has been demonstrated, reports attempting to compare the relative expression of these enzymes in malignant versus normal tissue have generated contradictory results [13-16].

Microarray technology constitutes a more recent approach for the detection and quantification of gene expression in a particular type of tissue. This technique allows for direct analysis of the expression of thousands of different genes at the same time; it is therefore a powerful tool for the study of differential patterns of expression in normal and tumour tissue.

This study involved the analysis of 17 normal specimens and 104 breast cancer biopsies. Whole genome expression microarrays were used in an attempt to identify differences in the expression profiles of normal and malignant breast tissue specimens.

\section{Materials and methods}

Patient selection

Tissue specimens from 104 cases of primary breast cancer (prior to any treatment with tamoxifen or chemotherapeutic agents), on which clinical follow-up and pathologic material, including snap-frozen tissue, were available for analysis from the 1993-1997 files of St Vincent's University Hospital Pathology Department, Dublin, Ireland, were included in this study. The patients involved underwent potentially curative resection at the hospital. Unfixed fresh breast resection specimens were received in Pathology Laboratory within maximum $30 \mathrm{~min}$ of resection. The tissue was examined macroscopically and samples of tumour snap frozen in liquid nitrogen and subsequently stored at $-70^{\circ} \mathrm{C} /-80^{\circ} \mathrm{C}$ prior to RNA isolation. A number of clinical and pathological parameters were abstracted from patients' charts including details on age, post-operative treatment and follow-up, tumour stage, and hormonal analysis. Pathologic material was examined on each case by SK. Tumours were typed [17] and graded [18] as previously described. Staging was performed according to the TNM system of the UICC [19]. Seventeen non-cancerous breast biopsies were also included in these studies to represent normal breast tissue.

\section{RNA extraction}

For RNA analyses, dissected tumours that had been snapfrozen in liquid nitrogen and then stored at $-70^{\circ} \mathrm{C} /-80^{\circ} \mathrm{C}$ until required were homogenised, on ice, in $1 \mathrm{ml}$ TriReagent (Sigma; Poole, UK) and total RNA was subsequently isolated according to the manufacturer's instructions. RNA quantity and purity were assessed at $260 \mathrm{~nm}$ and $280 \mathrm{~nm}$ using a Nanodrop (ND-1000; Labtech. International); an Agilent bioanalyser (Agilent 2100; Agilent Technologies) was used to assess RNA qualitatively after isolation and, subsequently, following biotin-labelling and after fragmentation.

\section{Microarray analysis}

About $100 \mathrm{ng}$ of each specimen was amplified and labelled using the Affymetrix GeneChip Eukaryotic 2 Cycle Labelling Assays for Expression Analysis, (Affymetrix; 900494) according to the manufacturer's instructions (www.af fymetrix.com/products/reagents/specific/cdna2.affx). Gene expression was examined using whole genome microarrays (Affymetrix; U133 Plus 2.0; 900470). Microarray hybridisation, normalisation and filtering were performed as we have previously described [20].

\section{Statistical analysis}

Statistical (univariate and multivariate) analyses of the results were performed using the SPSS 10.1 software package. Descriptive statistics were used to summarise patient characteristics and statistical analysis of the results was performed using Pearson's $X^{2}$ test to investigate relationships between mRNA expression and clinicopathological and histopathologic findings. Kaplan-Meier survival curves were established and were subsequently checked using the log-rank, Breslow and Tarone-ware tests $(P$-values represent log-rank, unless otherwise indicated) to assess the prognostic significance of expression of analysed mRNAs in tumour cells. Multivariate survival analyses were performed using the Cox regression backward stepwise likelihood ratio. The data was censored at 5 years for multivariate analysis. A value of $P<0.05$ was considered statistically significant.

\section{Results}

Patient characteristics

This study involved analysis of 104 breast cancer biopsies (removed prior to any treatment with tamoxifen or chemotherapeutic agents) from patients aged between 31 years 
and 89 years at the time of diagnosis (mean age $=58$ years). Twenty-seven were less than 50 years and seventyseven women were 50 years, or older, at diagnosis.

The size of the tumours ranged between $0.6 \mathrm{~cm}$ and $8.0 \mathrm{~cm} \quad($ mean $=2.79 \mathrm{~cm})$. Eighteen tumours were $\mathrm{T} 1$ $(<2 \mathrm{~cm})$ in maximal dimension; 83 were $\mathrm{T} 2(2-5 \mathrm{~cm})$ and 3 tumours were T3 $(>5 \mathrm{~cm})$. Eighty-two were invasive ductal carcinoma, 17 were invasive lobular and five were tumours of special type (two tubular and three mucinous). Eleven tumours were grade 1; 40 were grade 2; and 53 were grade 3 . Sixty-seven tumours were oestrogen receptor (ER) positive and 34 were ER negative (ER status was determined by Enzyme Immuno-Assay (EIA); a positive result was defined as more than $200 \mathrm{fmol} / \mathrm{g}$ protein). ER status was not available for 3 patients. Forty-five tumours had no axillary metastases and 59 tumours had metastasised to axillary lymph nodes.

Sixty-nine women were treated with post-operative tamoxifen; 26 did not receive tamoxifen. Fifty patients were treated with adjuvant systemic chemotherapy (CMF +/- adriamycin); 45 patients did not receive chemotherapy. Details regarding tamoxifen and systemic chemotherapy were not available for 9 patients. Maximal follow-up was 3,026 days with a mean follow-up of 1,887 days.

Expression of drug-metabolism related genes

The presence of mRNAs from several different drug metabolism-related enzymes was detected in both normal and tumour tissue. As shown in Table 1, drug metabolismrelated genes appear to be frequently expressed in both normal and tumour tissue. Some of these genes also show differential regulation, their expression levels significantly changed in malignant as compared to normal tissue. Amongst the cytochromes P450, CYP2C8, CYP2D6, CYP2E1 and CYP2J2 show increased frequency of expression in tumour as compared to normal tissue, while CYP1A1, CYP2C18, CYP2W1 and CYP3A5 are more commonly found in normal than in tumour tissue. As for the (GSH)-related genes, only two appear to be differentially regulated in tumour and normal tissue. Expression of GSH transferase (GST) M4 mRNA is less frequent in tumour than in normal specimens, while that of GSH peroxidase 2 is more common in tumour tissue. The transcript for aryl hydrocarbon receptor nuclear translocator protein 2 (ARNT2) is also considerably more frequent in tumour than in normal specimens, suggesting that it could be used as a biomarker of disease.

Alterations in expression can be seen in a different aspect in Table 2, which shows significant changes in the expression of genes involved in drug metabolism as detected in normal and tumour tissue. In Table 2, changes in expression are stated as fold change between normal and tumour sample values; these values are related to the intensity of microarray probe binding and are expressed in arbitrary units. For every gene of interest, the microarray platform used has 11 different probes; Table 2 refers to the results obtained with specific probes, hence the existence of more than one entry for a single gene.

As can be seen in Table 2, frequency of expression does not necessarily correlate with changes in the expression levels of a particular gene; many of the genes listed in Table 1 are not differentially expressed in malignant as compared to normal tissue. The cytochromes P450 in this list are upregulated in tumour tissue, in accordance with the general tendency observed in P450 expression studies. The GSH-related genes, on the other hand, appear to be preferentially downregulated in tumour tissue, with the exception of GSH reductase, GST omega 2, GSH synthetase and one of the probes of GST A4.

For those genes that were commonly expressed (i.e., present in 15-85\% of specimens), the possibility of a correlation between level of expression and overall survival, relapse-free survival, relevance as a positive (good) or negative (bad) prognostic factor, age at diagnosis, ER status, lymph node spread, tumour type, tumour size and tumour grade was analysed. The results shown in Table 3 indicate that expression of ARNT2 positively correlates with patient survival, while GST A1 is associated with poorer prognosis.

Prognostic analysis of ARNT2 and GST A1 for diseasefree survival and overall survival

To further understand the implications of our findings, patient disease-free survival was plotted relative to the presence or absence of GST A1 and ARNT2 (Fig. 1). The graphs shown in Fig. 1 present censored data: this means that the data have been corrected by taking into account those patients for whom complete follow-up information was not available. This is a common event in this type of study: some patients move to a different place, or no longer attend follow-up clinics. Their data are therefore included in the study, but only up to the last time that information was available on their status. After that, they're no longer considered for the statistics calculations.

In relation to relapse-/disease-free survival (RFS), Kaplan-Meier analysis indicated ARNT2 expression to be a favourable factor associated with extended RFS (Fig. 1(i); $P=0.0094$ ) and overall survival (OS) (Fig. 1(ii); $P=$ 0.0018 ) from time of diagnosis. This was supported by $X^{2}$ analysis (Table 4), indicating ARNT2 presence to be significantly associated with smaller tumour sizes $(P=0.006)$ and with relapse-free survival $(P=0.027)$ and 
Table 1 Expression of members of the cytochrome P450 superfamily, glutathione-related genes and drug metabolism-related transcription factors in breast tissue samples expressed as percentage of samples positive for each particular gene

\begin{tabular}{|c|c|c|c|}
\hline Gene ID & Gene name & Normal (\%) & Tumour (\%) \\
\hline NM_000499 & CYP1A1 & 23.5 & 6.7 \\
\hline NM_000761 & CYP1A2 & 88 & 96 \\
\hline NM_000104 & CYP1B1 & 100 & 100 \\
\hline NM_000762 & CYP2A6 & 35.3 & 30.5 \\
\hline NM_000767 & CYP2B6 & 0 & 4.8 \\
\hline NM_000770 & CYP2C8 & 11.8 & 4.8 \\
\hline NM_030878 & CYP2C8 & 5.9 & 31.4 \\
\hline NM_000771 & CYP2C9 & 17.6 & 5.7 \\
\hline NM_000772 & CYP2C18 & 41.2 & 15.2 \\
\hline NM_000106 & CYP2D6 & 11.8 & 52.4 \\
\hline AF182276 & CYP2E1 & 47 & 77 \\
\hline NM_000775 & CYP2J2 & 35.3 & 79 \\
\hline NM_024514 & CYP2R1 & 11.8 & 33.3 \\
\hline ВC012027 & CYP2U1 & 0 & 1 \\
\hline NM_017781 & CYP2W1 & 47 & 33.3 \\
\hline NM_017460 & CYP3A4 & 58.8 & 61.9 \\
\hline NM_022820 & CYP3A43 & 11.8 & 9.5 \\
\hline NM_000777 & CYP3A5 & 58.8 & 13.3 \\
\hline NM_000765 & CYP3A7 & 23.5 & 30.5 \\
\hline NM_000941 & NADPH cytochrome P450 oxidoreductase & 82 & 95 \\
\hline NM_000846 & Glutathione transferase $\mathrm{A} 1$ & 23.5 & 18.1 \\
\hline NM_000847 & Glutathione transferase A3 & 5.9 & 10.5 \\
\hline NM_001512 & Glutathione transferase A4 & 100 & 100 \\
\hline NM_015917 & Glutathione transferase $\mathrm{K} 1$ & 100 & 100 \\
\hline NM_000561 & Glutathione transferase M1 & 94.1 & 76.2 \\
\hline NM_000848 & Glutathione transferase $\mathrm{M} 2$ & 94.1 & 95.2 \\
\hline A1459140 & Glutathione transferase M3 & 94 & 81 \\
\hline NM_000850 & Glutathione transferase M4 & 52.9 & 21.9 \\
\hline NM_000851 & Glutathione transferase M5 & 100 & 92.4 \\
\hline NM_004832 & Glutathione transferase $\mathrm{O} 1$ & 100 & 100 \\
\hline NM_000852 & Glutathione transferase P1 & 100 & 100 \\
\hline NM_000853 & Glutathione transferase $\mathrm{T} 1$ & 76.5 & 80 \\
\hline NM_000854 & Glutathione transferase $\mathrm{T} 2$ & 23.5 & 39 \\
\hline NM_001498 & Gamma glutamyl cysteine synthetase, heavy subunit & 100 & 98.1 \\
\hline NM_002061 & Gamma glutamyl cysteine synthetase, light subunit & 100 & 98.1 \\
\hline NM_005265 & Gamma glutamyl transpeptidase & 88.2 & 97.1 \\
\hline NM_000581 & Glutathione peroxidase 1 & 100 & 100 \\
\hline NM_002083 & Glutathione peroxidase 2 & 23.5 & 50.5 \\
\hline NM_002084 & Glutathione peroxidase 3 & 94.1 & 98.1 \\
\hline NM_002085 & Glutathione peroxidase 4 & 100 & 100 \\
\hline NM_003996 & Glutathione peroxidase 5 & 5.9 & 1.9 \\
\hline NM_000637 & NADPH Glutathione reductase & 47.1 & 61 \\
\hline NM_001621 & Aryl hydrocarbon receptor & 100 & 98.1 \\
\hline NM_014862 & Aryl hydrocarbon receptor nuclear translocator protein 2 & 17.6 & 75.2 \\
\hline
\end{tabular}


Table 2 List of drug metabolism-related genes with significant changes in expression levels in tumour relative to normal breast tissue

\begin{tabular}{|c|c|c|c|c|c|}
\hline Probe set & Gene name & Normals & Tumours & Fold change & $P$ value \\
\hline 202435_s_at & CYP1B1 & 649 & 973 & 1.5 & 0.018 \\
\hline 214320_x_at & CYP2A6 & 37 & 472 & 12.8 & 0.008 \\
\hline 1494_f_at & CYP2A6 & 37 & 394 & 10.7 & 0.023 \\
\hline 200736_s_at & Glutathione peroxidase 1 & 4,152 & 1,867 & -2.2 & $<0.001$ \\
\hline 214091_s_at & Glutathione peroxidase 3 & 2,159 & 169 & -12.8 & $<0.001$ \\
\hline 201348_at & Glutathione peroxidase 3 & 3,189 & 210 & -15.2 & $<0.001$ \\
\hline 201106_at & Glutathione peroxidase 4 & 5,192 & 2,084 & -2.50 & $<0.001$ \\
\hline 225609_at & Glutathione reductase & 259 & 494 & 1.9 & $<0.001$ \\
\hline 235405_at & Glutathione S-transferase A4 & 58 & 173 & 3.0 & $<0.001$ \\
\hline 202967_at & Glutathione S-transferase A4 & 314 & 204 & -1.5 & 0.005 \\
\hline 217751_at & Glutathione S-transferase kappa 1 & 1,294 & 953 & -1.4 & 0.027 \\
\hline 227163_at & Glutathione S-transferase omega 2 & 60 & 323 & 5.3 & $<0.001$ \\
\hline 203815_at & Glutathione S-transferase theta 1 & 550 & 242 & -2.3 & 0.019 \\
\hline 201415_at & Glutathione synthetase & 273 & 491 & 1.8 & $<0.001$ \\
\hline
\end{tabular}

Fold change is calculated as intensity values of nomal/intensity values of tumours

overall survival $(P=0.002) 5$ years after breast cancer diagnosis.

In contrast to ARNT2, Kaplan-Meier analysis indicated GST A1 presence in tumours to be significantly associated with shortened RFS (Fig. 1(iii); $P=0.0131$ ) and OS (Fig. 1(iv); $P=0.0028$ ) times from breast cancer diagnosis. As summarised in Table 4, this is in agreement with $X^{2}$ analysis indicating GST A1 to be associated with spread of cancer to lymph nodes $(P=0.031)$ and with relapse $(P=0.006)$ and death $(P=0.001)$ from breast cancer within 5 years of diagnosis. Furthermore, multivariate analysis (Table 5) indicated GST A1 expression $(P=0.045)$, as well as lymph node status $(P<0.0005)$, tumour grade $(P=0.003)$, and ER status $(P=0.0026)$ to be independent prognostic factors for OS.

\section{Discussion}

A number of studies have clearly demonstrated that cytochromes P450 and other drug-metabolism related enzymes are commonly expressed in both normal and tumour tissue. Literature also suggests a differential regulation of these enzymes in malignant cells, although the nature of these differences is still a matter of controversy.

Analysis of a large number of breast tumour specimens was performed in our laboratory using whole genome gene expression microarrays. A large proportion of the specimens studied expressed a variety of drug metabolismrelated genes; in many cases, significant alterations in gene expression were found in tumour as compared to normal specimens.
It is known that the expression of CYP2J2 increases cell proliferation and inhibits apoptosis [10], so it is not unexpected that CYP2J2 mRNA was more often expressed in tumours than in normal tissue. CYP2W1, however, has recently been hailed as a tumour-specific P450 [21], with no or very low levels of CYP2W1 mRNA and protein found in normal adult tissues, so it was unexpected to find that mRNA expression of this enzyme in normal tissue was more frequent than in tumour specimens. The low prevalence of CYP1A1 mRNA expression found in this analysis is in agreement with previous results reporting lower frequency of CYP1A1 expression in tumour as compared to normal tissue [22]. Very low levels of this enzyme were also found in both breast tumour specimens and their surrounding normal tissue by RT-PCR analysis [14]. However, the same authors found decreased expression of CYP2E1 in tumour specimens by immunoblotting, which is in contradiction with the observed mRNA expression frequencies in our results. These inconsistencies could be attributed to posttranscriptional events, since mRNA levels do not always correlate with protein levels.

GSH transferase M4 (GST M4) mRNA expression was found to be more common in normal than tumour tissue. The role played by this enzyme in cancer remains obscure, but a recent study suggested an association between GST M4 polymorphisms and lung cancer risk, implying that the activity of this enzyme might be involved in tumour development [23]. GSH peroxidase 2 mRNA was also found to be more frequently expressed in tumour as compared to normal breast tissue; this enzyme can protect cells from free radicals and also regulate proliferation and apoptosis through redox signalling [24] and thus its 


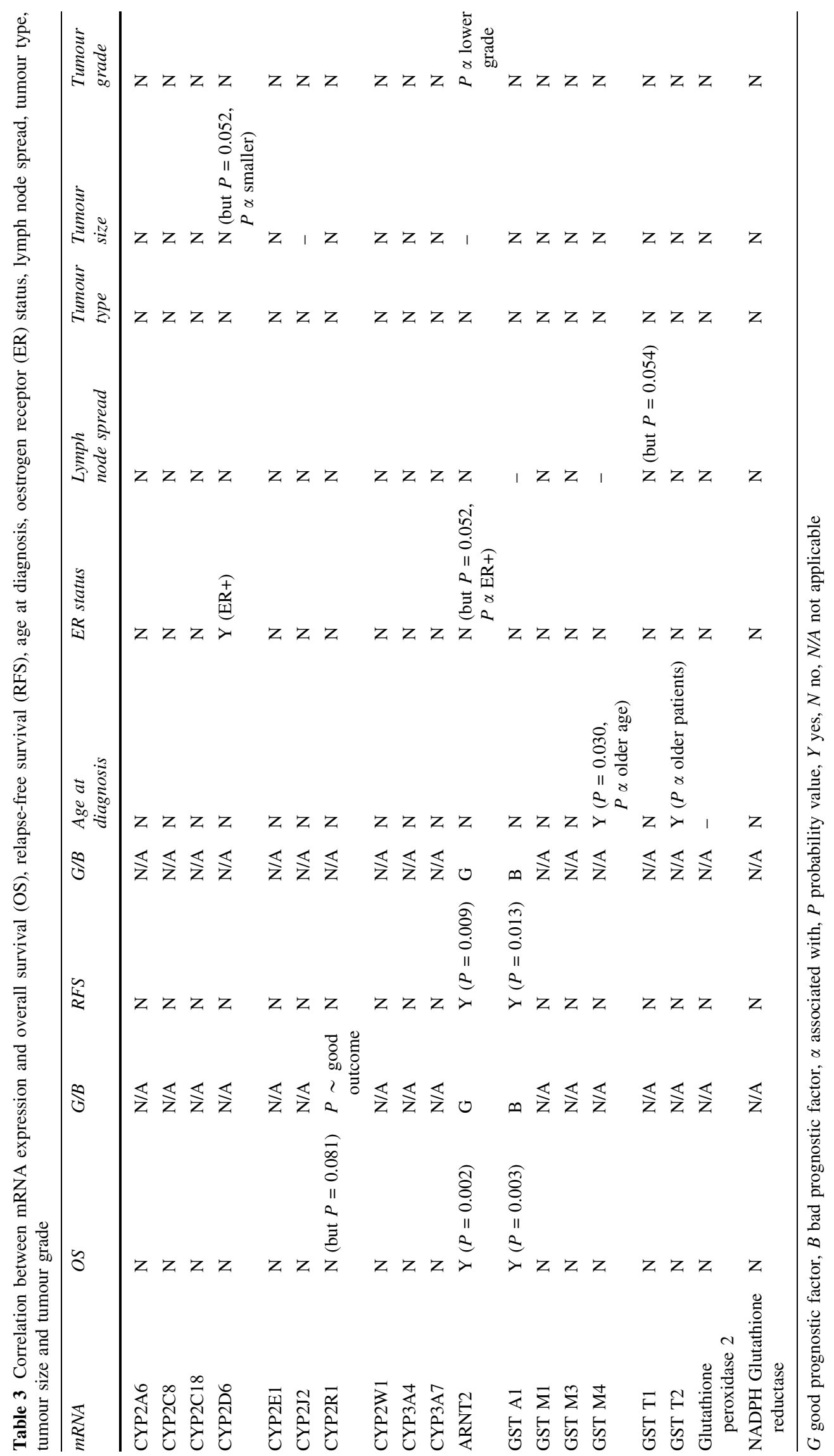


Fig. 1 Kaplan-Meier survival curves for ARNT2 ((i) \& (ii)) and GST A1 ((iii) \& (iv)) mRNA presence or absence and their association with disease/ relapse-free survival (RFS) and overall survival (OS), respectively

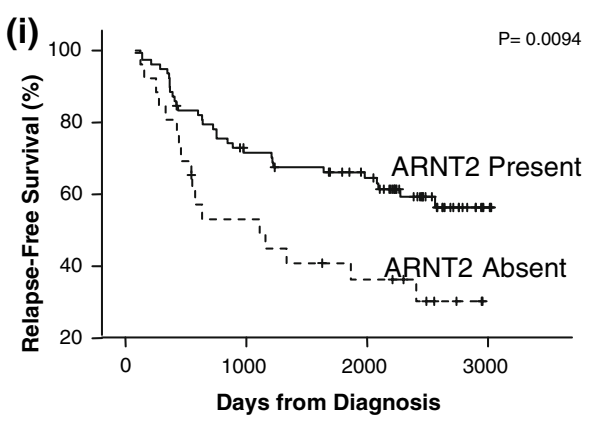

(iii)

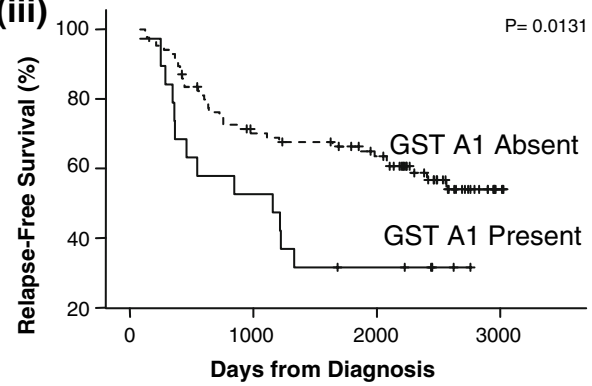

(ii)

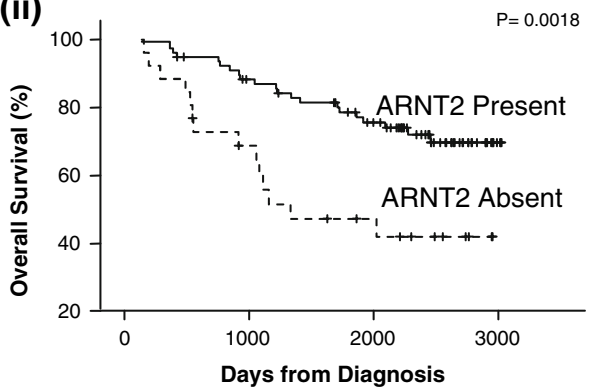

(iv)

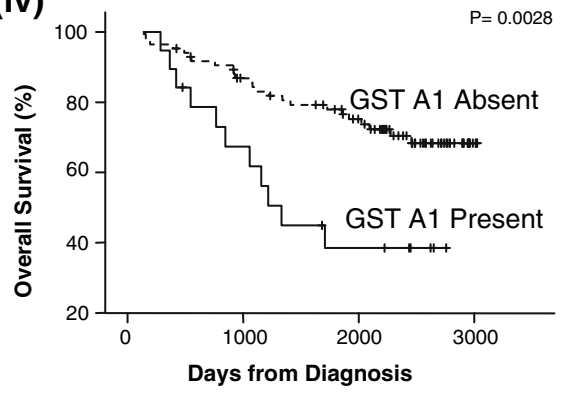

Table 4 Correlation between clinicopathological factors and expression of GST A1 and ARNT2 mRNA in breast carcinoma

\begin{tabular}{|c|c|c|c|c|c|c|}
\hline Characteristics & No. of cases & GST A1 (\%) & $P$ & No. of cases & ARNT2 (\%) & $P$ \\
\hline \multicolumn{7}{|l|}{ Age (yr) } \\
\hline$<50$ & $6 / 27$ & 22.2 & \multirow[t]{2}{*}{0.537} & $18 / 27$ & 66.7 & \multirow[t]{2}{*}{0.245} \\
\hline$\geq 50$ & $13 / 77$ & 16.9 & & $60 / 77$ & 77.9 & \\
\hline \multicolumn{7}{|l|}{ Tumour size } \\
\hline$<2.8 \mathrm{~cm}$ & $11 / 56$ & 19.6 & \multirow[t]{2}{*}{0.695} & $48 / 56$ & 85.7 & \multirow[t]{2}{*}{$0.006 *$} \\
\hline$\geq 2.8 \mathrm{~cm}$ & $8 / 48$ & 16.7 & & $30 / 48$ & 62.5 & \\
\hline \multicolumn{7}{|l|}{ Lymph node metastasis } \\
\hline Negative & $4 / 45$ & 8.9 & \multirow[t]{2}{*}{$0.031^{*}$} & $33 / 45$ & 73.3 & \multirow[t]{2}{*}{0.732} \\
\hline Positive & $15 / 59$ & 25.4 & & $45 / 59$ & 76.3 & \\
\hline \multicolumn{7}{|l|}{ Histology grade } \\
\hline I & $1 / 11$ & 9.1 & \multirow[t]{3}{*}{0.453} & $10 / 11$ & 90.9 & \multirow[t]{3}{*}{0.084} \\
\hline II & $6 / 40$ & 15.0 & & $33 / 40$ & 82.5 & \\
\hline III & $12 / 53$ & 22.6 & & $35 / 53$ & 66.0 & \\
\hline \multicolumn{7}{|l|}{ Histology type } \\
\hline IDC & $17 / 82$ & 20.7 & \multirow[t]{3}{*}{0.381} & $58 / 82$ & 70.7 & \multirow[t]{3}{*}{0.132} \\
\hline ILC & $2 / 17$ & 11.8 & & $15 / 17$ & 88.2 & \\
\hline Special & $0 / 5$ & 0.0 & & $5 / 5$ & 100.0 & \\
\hline \multicolumn{7}{|l|}{ ER status } \\
\hline Negative & $9 / 34$ & 26.5 & \multirow[t]{2}{*}{0.106} & $22 / 34$ & 64.7 & \multirow[t]{2}{*}{0.052} \\
\hline Positive & $9 / 67$ & 13.4 & & $55 / 67$ & 82.1 & \\
\hline \multicolumn{7}{|l|}{ Relapse } \\
\hline No relapse at 5 yrs & $5 / 54$ & 9.3 & \multirow[t]{2}{*}{$0.006^{*}$} & $45 / 54$ & 83.3 & \multirow[t]{2}{*}{$0.027 *$} \\
\hline Relapsed within 5 yrs & $13 / 41$ & 31.7 & & $26 / 41$ & 63.4 & \\
\hline \multicolumn{7}{|c|}{ Alive versus died from breast cancer } \\
\hline Alive \& well at 5 yrs & $6 / 64$ & 9.4 & \multirow[t]{2}{*}{$0.001 *$} & $54 / 64$ & 84.4 & \multirow[t]{2}{*}{$0.002 *$} \\
\hline Died within 5 yrs & $11 / 29$ & 37.9 & & $16 / 29$ & 55.2 & \\
\hline
\end{tabular}

$P$ values from $X^{2}$ analyses; * indicates significant parameter; $I D C$ invasive ductal carcinoma, $I L C$ invasive lobular carcinoma 
Table 5 Multivariate cox regression backward stepwise (likelihood ratio)

\begin{tabular}{lcc}
\hline Characteristics & Overall survival (OS), $P$ & Relapse-free survival (RFS), $P$ \\
\hline Lymph Node (spread versus no spread) & $<0.0005^{*}$ & $<0.0005^{*}$ \\
Histology grade (I \& II versus III) & $0.003^{*}$ & NS \\
Tumour size ( $<2.8 \mathrm{~cm}$ vs. $\geq 2.8 \mathrm{~cm})$ & $(0.060)$ & $0.048^{*}$ \\
ER status (positivity versus negativity) & $0.026^{*}$ & $<0.0005^{*}$ \\
GST A1 & $0.045^{*}$ & $\mathrm{NS}$
\end{tabular}

Parameters included in the multivariate analysis included age at diagnosis, tumour size, tumour grade, lymph node status, ER status, as well as GST A1 and ARNT2 mRNA expression. Mean size $(2.8 \mathrm{~cm})$ was used as cut-off; grade I \& II were grouped together versus grade III. This Table summarises significant factors. (* significant; $N S$ not significant)

increased expression may confer a survival advantage to tumour cells. Expression of GSH peroxidase 2 has been established in breast tissue [25] and increased expression of this enzyme has recently been reported in lung adenocarcinomas and in normal alveolar epithelium from smokers as compared to normal lung tissue from non-smokers [26].

Differential mRNA expression of ARNT2 was one of the major findings in our study, with expression in tumour tissue being much more prevalent than in normal tissue specimens and significantly correlating with better prognosis. To date, no correlation has been reported in the literature between expression of this gene and cancer progression or survival. It should be noted, however, that increased mRNA expression of an AhR-related element, the aryl hydrocarbon interacting protein, was also reported in specimens from patients that had a better prognosis [27]. This points to the AhR receptor pathway as a commonly altered target in breast cancer; its deregulation, however, appears to be associated with good prognosis.

Upon binding a specific ligand, the aryl hydrocarbon receptor $(\mathrm{AhR})$ dimerises with the $\mathrm{AhR}$ nuclear translocator protein (ARNT) and activates the transcription of its target genes. ARNT2 is a homolog of ARNT with a more restricted pattern of expression, commonly found in the central nervous system [28], although its expression has also been reported in other developing organs such as kidney [29]. The main function of ARNT2 appears to be in organ development, since knock-out or disruption of this gene in mice and zebrafish results in severe defects in organs such as brain, eyes, heart and gut [30, 31].

The AhR receptor pathway is implicated in such essential cell functions as growth, proliferation, apoptosis and epithelial-mesenchymal transition [32]. The role of the AhR in these phenomena remains undefined, as there is evidence that it can both increase and inhibit cell proliferation, as well as protect cells from apoptosis or induce cell death. One of the best characterised mechanisms of growth inhibition by the AhR involves repression of ER signalling; it is then not unreasonable to believe that ER positive tumours would display impaired growth and decreased proliferation rates. It should also be noted that even though ER expression did not significantly correlate with ARNT2 expression, the $P$ value was almost significant $(P=0.052)$. This would suggest that many of the tumours expressing ARNT2 were also ER+. AhR signalling, helped by ARNT2, might then slow down the progression of these tumours. This model would explain the better prognosis observed in patients with ARNT2-overexpressing tumours.

It should be noted that ER positive tumours are associated with better survival; since many of the tumours expressing ARNT2 are also ER positive, the better survival rates associated with ARNT2 might just be due to the fact that this protein is linked with ER positive status, which in turn is associated with better survival. Increased ARTN2 mRNA expression might thus not directly impair tumour progression but rather be associated with the better prognosis-related ER positive status. Even if this were the case, ARNT2 would still be useful in prediction of prognosis and might also be used as a marker of disease, since it is considerably upregulated in tumour as opposed to normal tissue.

Expression of GST A1 was associated with decreased overall and relapse-free survival. This might be related to therapy efficacy, since expression of GST A1 in cell lines is associated with an increase in resistance to carboplatin and cyclophosphamide [33]. Increased expression of GST A1 in tumour tissue would mean enhanced inactivation of anticancer drugs that could result in treatment failure.

Several authors have investigated whether a correlation exists between GST A1 expression in tumours and disease prognosis, sometimes generating contradictory results. Early studies carried out in breast cancer patients failed to establish a correlation between GST expression and clinicopathological features such as disease-free and overall survival [34, 35]. Confirming these results, no association was found between the expression of any of the GSTs analysed and response to treatment, overall survival and disease-free survival in ovarian cancer [36]. However, a more recent analysis found that patients homozygous for a GST A1 polymorphism that results in reduced expression of the enzyme showed a significant difference in 5-year survival after breast cancer treatment when compared to heterozygous patients [37]; indeed, low expression of GST 
A1 correlated with reduced risk of death in the 5 years following diagnosis. Lower expression of GST A1 in the liver would mean that drugs such as cyclophosphamide are inactivated in a slower manner, leaving more drug available in the circulation and improving therapy efficacy.

In conclusion, gene expression microarray analysis makes possible the study of alterations in the expression of thousands of genes during cancer development and progression, providing an accurate picture of what is happening inside the cell. As shown by our results, it can also help to elucidate the connection between gene expression and cancer phenotype or therapy outcome, thereby improving our knowledge of the disease and providing biomarkers for diagnosis and individual tumour characterisation.

Acknowledgments This work was supported by funding from Ireland's Higher Educational Authority Programme for Research in Third Level Institutions (PRTLI) Cycle 3, equipment funding from Science Foundation Ireland, Dublin City University's Albert College Fellowship, Dublin City University's Research Fellowship, and the Health Research Board.

\section{References}

1. Perquin M, Oster T, Maul A, Froment N, Untereiner M, Bagrel D (2000) The glutathione-related detoxification pathway in the human breast: a highly coordinated system disrupted in the tumour tissues. Cancer Lett 1:7-16

2. Balendiran GK, Dabur R, Fraser D (2004) The role of glutathione in cancer. Cell Biochem Funct 6:343-352

3. Oyama T, Kagawa N, Kunugita N, Kitagawa K, Ogawa M, Yamaguchi T, Suzuki R, Kinaga T, Yashima Y, Ozaki S et al (2004) Expression of cytochrome P450 in tumor tissues and its association with cancer development. Front Biosci 1967-1976

4. Nebert DW, Dalton TP (2006) The role of cytochrome P450 enzymes in endogenous signalling pathways and environmental carcinogenesis. Nat Rev Cancer 12:947-960

5. Rodriguez-Antona C, Ingelman-Sundberg M (2006) Cytochrome P450 pharmacogenetics and cancer. Oncogene 11:1679-1691

6. Nelson DR, Koymans L, Kamataki T, Stegeman JJ, Feyereisen R, Waxman DJ, Waterman MR, Gotoh O, Coon MJ, Estabrook RW et al (1996) P450 superfamily: update on new sequences, gene mapping, accession numbers and nomenclature. Pharmacogenetics 1:1-42

7. Yu LJ, Matias J, Scudiero DA, Hite KM, Monks A, Sausville EA, Waxman DJ (2001) P450 enzyme expression patterns in the NCI human tumor cell line panel. Drug Metab Dispos 3:304-312

8. Dhaini HR, Thomas DG, Giordano TJ, Johnson TD, Biermann JS, Leu K, Hollenberg PF, Baker LH (2003) Cytochrome P450 CYP3A4/5 expression as a biomarker of outcome in osteosarcoma. J Clin Oncol 13:2481-2485

9. Nebert DW, Vasiliou V (2004) Analysis of the glutathione Stransferase (GST) gene family. Hum Genomics 6:460-464

10. Jiang JG, Chen CL, Card JW, Yang S, Chen JX, Fu XN, Ning YG, Xiao X, Zeldin DC, Wang DW (2005) Cytochrome P450 2J2 promotes the neoplastic phenotype of carcinoma cells and is upregulated in human tumors. Cancer Res 11:4707-4715

11. Adler V, Yin Z, Fuchs SY, Benezra M, Rosario L, Tew KD, Pincus MR, Sardana M, Henderson CJ, Wolf CR et al (1999) Regulation of JNK signaling by GSTp. EMBO J 5:1321-1334
12. Tew KD, Ronai Z (1999) GST function in drug and stress response. Drug Resist Updat 3:143-147

13. Murray GI, Taylor MC, McFadyen MC, McKay JA, Greenlee WF, Burke MD, Melvin WT (1997) Tumor-specific expression of cytochrome P450 CYP1B1. Cancer Res 14:3026-3031

14. Iscan M, Klaavuniemi T, Coban T, Kapucuoglu N, Pelkonen O, Raunio H (2001) The expression of cytochrome P450 enzymes in human breast tumours and normal breast tissue. Breast Cancer Res Treat 1:47-54

15. Muskhelishvili L, Thompson PA, Kusewitt DF, Wang C, Kadlubar FF (2001) In situ hybridization and immunohistochemical analysis of cytochrome P450 1B1 expression in human normal tissues. J Histochem Cytochem 229-236

16. Kapucuoglu N, Coban T, Raunio H, Pelkonen O, Edwards RJ, Boobis AR, Iscan M (2003) Expression of CYP3A4 in human breast tumour and non-tumour tissues. Cancer Lett 1:17-23

17. Page DL, Andersen AT (1987) Diagnostic histopathology. Churchill Livingstone, London, Melbourne and New York

18. Elston CW, Ellis IO (1991) Pathological prognostic factors in breast cancer. I. The value of histological grade in breast cancer: experience from a large study with long-term follow-up. Histopathol 403-410

19. Sobin LH, Wittekind C (1997). TNM classification of malignant tumours. John Wiley and Sons, New York

20. O'Driscoll L, McMorrow J, Doolan P, McKiernan E, Mehta JP, Ryan E, Gammell P, Joyce H, O'Donovan N, Walsh N et al (2006) Investigation of the molecular profile of basal cell carcinoma using whole genome microarrays. Mol Cancer 74

21. Karlgren M, Gomez A, Stark K, Svard J, Rodriguez-Antona C, Oliw E, Bernal ML, Ramon y Cajal S, Johansson I, IngelmanSundberg M (2006) Tumor-specific expression of the novel cytochrome P450 enzyme, CYP2W1. Biochem Biophys Res Commun 2:451-458

22. El-Rayes BF, Ali S, Heilbrun LK, Lababidi S, Bouwman D, Visscher D, Philip PA (2003) Cytochrome p450 and glutathione transferase expression in human breast cancer. Clin Cancer Res 5:1705-1709

23. Liloglou T, Walters M, Maloney P, Youngson J, Field JK (2002) A T2517C polymorphism in the GSTM4 gene is associated with risk of developing lung cancer. Lung Cancer 2:143-146

24. Brigelius-Flohe R, Muller C, Menard J, Florian S, Schmehl K, Wingler K (2001) Functions of GI-GPx: lessons from seleniumdependent expression and intracellular localization. Biofactors 14:101-106

25. Chu FF, Esworthy RS, Lee L, Wilczynski S (1999) Retinoic acid induces Gpx2 gene expression in MCF-7 human breast cancer cells. J Nutr 10:1846-1854

26. Woenckhaus M, Klein-Hitpass L, Grepmeier U, Merk J, Pfeifer M, Wild P, Bettstetter M, Wuensch P, Blaszyk H, Hartmann A et al (2006) Smoking and cancer-related gene expression in bronchial epithelium and non-small-cell lung cancers. J Pathol 2:192-204

27. van't Veer LJ, Dai H, van de Vijver MJ, He YD, Hart AA, Mao M, Peterse HL, van der Kooy K, Marton MJ, Witteveen AT et al (2002) Gene expression profiling predicts clinical outcome of breast cancer. Nature 6871:530-536

28. Maltepe E, Keith B, Arsham AM, Brorson JR, Simon MC (2000) The role of ARNT2 in tumor angiogenesis and the neural response to hypoxia. Biochem Biophys Res Commun 1:231-238

29. Freeburg PB, Abrahamson DR (2004) Divergent expression patterns for hypoxia-inducible factor-1beta and aryl hydrocarbon receptor nuclear transporter-2 in developing kidney. J Am Soc Nephrol 10:2569-2578

30. Hosoya T, Oda Y, Takahashi S, Morita M, Kawauchi S, Ema M, Yamamoto M, Fujii-Kuriyama Y (2001) Defective development 
of secretory neurones in the hypothalamus of Arnt2-knockout mice. Genes Cells 4:361-374

31. Hsu HJ, Wang WD, Hu CH (2001) Ectopic expression of negative ARNT2 factor disrupts fish development. Biochem Biophys Res Commun 2:487-492

32. Schlezinger JJ, Liu D, Farago M, Seldin DC, Belguise K, Sonenshein GE, Sherr DH (2006) A role for the aryl hydrocarbon receptor in mammary gland tumorigenesis. Biol Chem 9:11751187

33. Tanner B, Hengstler JG, Dietrich B, Henrich M, Steinberg P, Weikel W, Meinert R, Kaina B, Oesch F, Knapstein PG (1997) Glutathione, glutathione S-transferase alpha and pi, and aldehyde dehydrogenase content in relationship to drug resistance in ovarian cancer. Gynecol Oncol 1:54-62

34. Peters WH, Roelofs HM, van Putten WL, Jansen JB, Klijn JG, Foekens JA (1993) Response to adjuvant chemotherapy in primary breast cancer: no correlation with expression of glutathione S-transferases. Br J Cancer 1:86-92

35. Alpert LC, Schecter RL, Berry DA, Melnychuk D, Peters WP, Caruso JA, Townsend AJ, Batist G (1997) Relation of glutathione S-transferase alpha and mu isoforms to response to therapy in human breast cancer. Clin Cancer Res 5:661-667

36. Wrigley EC, McGown AT, Buckley H, Hall A, Crowther D (1996) Glutathione-S-transferase activity and isoenzyme levels measured by two methods in ovarian cancer, and their value as markers of disease outcome. Br J Cancer 6:763-769

37. Sweeney C, Ambrosone CB, Joseph L, Stone A, Hutchins LF, Kadlubar FF, Coles BF (2003) Association between a glutathione S-transferase A1 promoter polymorphism and survival after breast cancer treatment. Int J Cancer 6:810-814 